\title{
Interpretation of the Image of a Road as an Expression of Culturally Conditioned Perceptions Associated with the Concept of Time
}

\author{
Elena S. Mikitchenko \\ Department of Foreign Languages \\ Sanya University \\ Sanya, China \\ E-mail: homeuniversity@mail.ru
}

\begin{abstract}
The article presents the results of an experiment aimed to identify the peculiarities of national linguistic consciousness of the representatives of different cultures Russian and Chinese. The paper addresses the culturally conditioned notions and interpretations of time, associated with the image of a road/ path. The survey was conducted among Russian and Chinese students.
\end{abstract}

Keywords-world image; association experiment; time; image of a road/ path

\section{INTRODUCTION}

Time is one of the core aspects in understanding the world and the existence of a person in the world; it is an indispensable condition for implementing any changes. The changes to be implemented can only take place in space, thus space and time are inseparable from each other, and together they form a single space-time continuum. The concept of space-time unity was first introduced by a philosopher and art theorist M.M. Bakhtin as a metaphor (chronotope), where space penetrates into time and moves along with it, while time becomes a form of space: "Here time seems to get into space and flow through it forming roads, which is why the metaphors of a road are so rich and numerous" [2].

V. A. Plungyan also considers it feasible to resort to a metaphorical description interpreting the word "time" and distinguishes the following five "metaphorical blocks": time as a container - it contains an event taking place (during some event); time as a substance - it that can be measured (a lot of/ little time); time as a possession (to waste time); time as a destroyer (time has not been kind); and time as a traveler - it goes, moves, flies (time passes) [12]. M. A. Fedorov provides a more extended list of such metaphors: time as a person, time as a living being (it cannot wait, time is rushing by), time like water (time flows), etc. [19]

The represented image addressing temporal parameters is inevitably expressed through the spatial image, whilst this latter always has certain temporal characteristics: "Space, social system, a point in history is often very clearly reflected in the spatial image of a particular kind" - writes A. O. Yakimovich [20].
In Chinese culture, time has long been perceived as the eternal cycle of flowering and withering. The author of the book "Sima Qian — the historian" Ju. L. Kroll emphasizes the fact that in the ancient texts of all schools the term "time" (時) is used in the archaic meaning of particular, differently filled time intervals, favorable or unfavorable for any kinds of activities. The traditional Chinese thought had the opposition of "antiquity - modernity" (古今), which also meant "at all times" [6, 82-89]. Antiquity seemed to be an unattainable model, and Confucian views were reinforced by the expression: "The sky does not change, neither does Tao". As it is stated by A. D. Martynov, "according to Chinese ideas the march of history is a descent down from the top, while a person living in history is turned back to both present and future, and turned face to the past. Meanwhile, the Confucians believe that social order and the model of social behavior correspond to the Heavenly Tao Way", which means a person's life should conform to the principles of the world order and the rhythms of nature [7].

As A. E. Serikov suggests, the cyclic perception of time is to some extent inherent in all cultures. In many of them the cyclic time is accompanied by the linear, progressive movement and spiral life development. The same things are likewise characteristic of Chinese culture [15].

"In traditional Slavic culture, time was also perceived both mythologically (cyclically) and historically (linearly)" notes E. E. Stefansky. "Cyclic perception of time in the ancient Slavic cultures is captured in the common origin of the words "время" ("time") and “вертеть", "вращать" ("rotate"). The linear extension of human life was conceptualized in the lexemе "век" ("century"), associated with the words "виться", "развиваться" (“curve", "develop") [16]. "The circle as one of the oldest mythological symbols reflects the space-time notions of "one's own" and "others" space, as well as of the cyclicity of time and eternity" [17]. 


\section{EXPERIMENT TO IDENTIFY FEATURES OF THE NATIONAL LANGUAGE CONSCIOUSNESS IN RUSSIAN AND CHINESE STUDENT AUDIENCES}

\section{A. Method of the Experiment}

In order to identify the subjective image of a separate fragment of the worldview with its space-time and emotional-evaluative components, the word "road" was chosen. The main reason is that this concept not only represents the existence of some material object related to movement, but it also demonstrates the model of the spatial structure of the universe, which is inevitably linked to the way a person perceives the time flow and understands the deep philosophy of life journey.

Listing the items that constitute the fund of basic national values, G. D. Gachev among the rest also mentions the concept of a road: "... to identify the image of the world the integrity of national life and its components are considered. They include nature and its forces, daily life, folklore, language, imagery of poetics, correlation of space and time and their coordinates: distance, width, top, bottom, road, etc. Thus, they represent a set of main national values, reference points, symbols, archetypes, which then determines people's way of thinking" [4].

Referring to chronotope in art, E.L. Balkind suggests that when creating an image of time in a piece of art, there can be different time layers represented simultaneously, which reflects the aspiration to "appeal to eternity and universality of the event" [1].

"The Old Road" poem by N. Rubtsov illustrates this idea particularly well. What is happenings now also addresses distant past, future and eternity: "The clouds and clouds above ... In the mould of time, instant and invisible, as before, pilgrims continue their way ..."; "As tsars enjoyed the lavish palaces, I truly love the old roads and the blue eyes of eternity!"; "This is where the Russian spirit originates from, back in centuries. Nothing is happening here, but this spirit will remain for ages! Let the grass cover the road, and let the clouds flow above...". To compare, next are the lines from "Nineteen poems" by an unknown Chinese author, I-II centuries AD: "On their way, on their way, all the time on their way ... The clouds float, covering the white sun. Far from home, the wanderer does not remember the road home ..." [3]. Thus, we see how in such different cultures the images of time and road or way resonate with each other ("the sky does not change, neither does Tao"; "all the time on their way ..."; "the blue eyes of eternity", "... Nothing is happening here, but this spirit will remain for ages").

The perceptions people possess about space and time are laid down by the archetype of their native culture, fixed in the linguistic worldview and expressed in the associative and verbal model of the linguistic persona.

The conducted experiment involved sixty-seven Chinese students of the third year, who have come to the city of Sanya from different regions of China to study the Russian language. The students were given the task to describe a picture of an imaginary road, as if they were artists or film directors. The questions were asked in the Russian language and were rather specific and simple, for instance: "Where is the road that you imagine situated?", "What is the weather like in your picture?", "What is around the road?", "How do you feel when you see such a road?", "What is the road made of and what color is it?", etc. The majority of the students responded briefly, however sometimes they also provided very detailed answers. The same experiment had been previously carried out among sixty-four second year students of the Department of the Russian Language and Publishing at the Far Eastern State Humanitarian University of Khabarovsk.

\section{B. Results of the Experiment}

1) Visual and emotional representations of a road image: The results of the experiment aimed to identify the perception specifics of the national images of a road/path with Russian and Chinese students have already been presented in the articles "Associative experiment as a way of revealing the national and cultural content of lexical associations" [8]. "Psychological content and emotional assessment of mental perception of a road/path by Chinese students" [9], "Expressing the color symbolism of Chinese culture in visualizing the image of a road" [10], "Measuring length with mood, and width with light: national and cultural features of the image of a road" [11], etc.

As it was learned, the culturally conditioned visual and corresponding emotional perceptions of the image of a road of Chinese students are contrast to those expressed by Russian ones. While Chinese students give a cheerful and bright description of the modern high-speed roads in China with greenery and flowers, the emotional attitude of Russians to endless badly-maintained Russian roads was as earlier described by N. V. Gogol: "The happy traveler is the one who after a long and boring road with its cold, slush and mud ... finally sees the familiar roof ..." [5]. The shared views of the representatives of the two different cultures were revealed only comparing the space-time parameters of the image of a road.

2) Road image representations associated with the concept of the time: This article mainly focuses on the expression of culturally conditioned perceptions on the concept of time through the image of a road. Among the other questions listed in the questionnaire were also the following ones: "What season of the year is there in your picture of the road?", "What time of the day is it?", "Is the road long/short?", etc.

a) Seasons: The processed and analyzed data shows that Chinese students imagined the road in different seasons: in summer: $46 \%$, in spring: $21 \%$, in autumn: $20 \%$, in winter: $13 \%$. See "Fig. 1". 


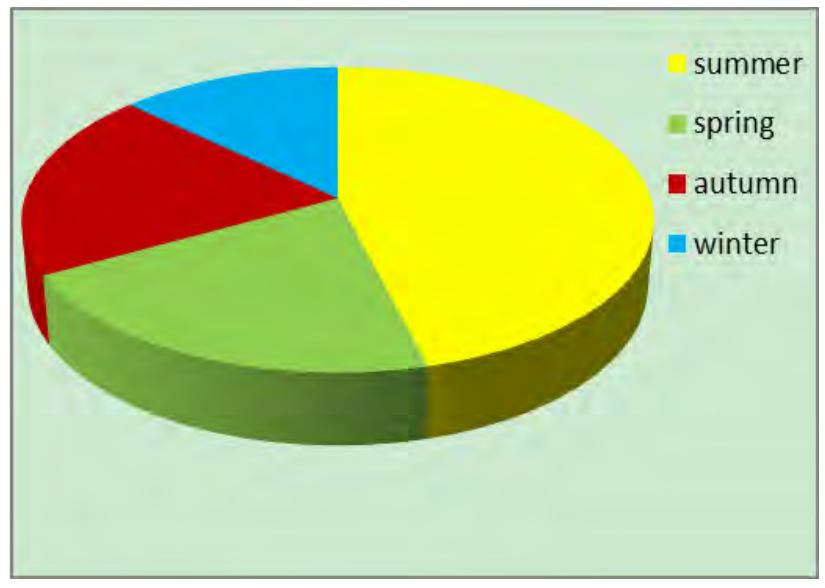

Fig. 1. Image of the road in the view of Chinese students. Seasons.

For Russian students we got the following figures: in summer: $63 \%$, in autumn: $29 \%$, in winter: $6 \%$, in spring: $2 \%$. See "Fig. 2".

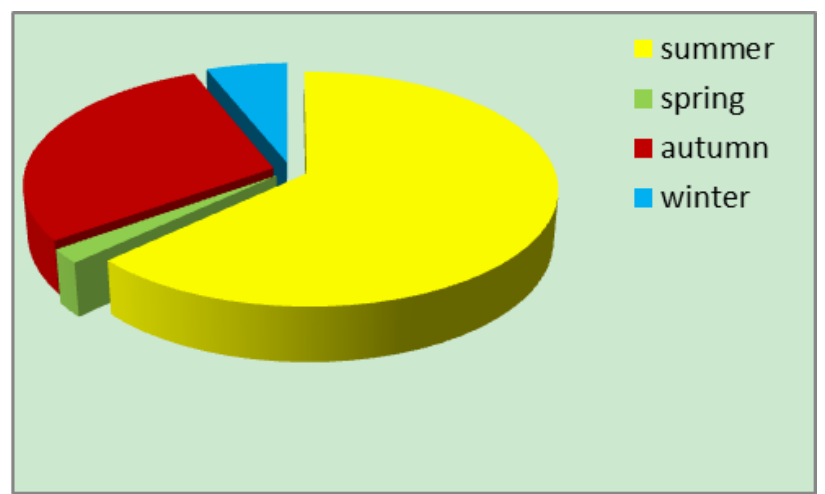

Fig. 2. Image of the road in the view of Russian students. Seasons.

Judging by the fact that the answers of Chinese interviewees for all seasons, except summer, spread nearly equally, it can be said that the climate conditions do not affect the formation of the road image as much as they do for Russian students, who hardly ever imagine it in winter and spring. Most often, both Chinese and Russian students have the images of a road in summer or autumn period (for Russians this is usually mid-summer or the beginning of autumn, the warm and dry season, which is weather conditioned - the road quality in rural areas tends to be poor in rainy seasons).

b) The time of day: As far as the time of the day is concerned, $48 \%$ of Chinese students imagine the picture of the road in the morning, $29 \%$ - in the afternoon, $23 \%$ - in the evening, $0 \%$ - at night. Here is already the observable difference with the Russian audience who mostly describe it in the afternoon (86\%), rarely in the morning (14\%) and never in the evening or at night $(0 \%)$. See "Fig. 3" and "Fig. 4".

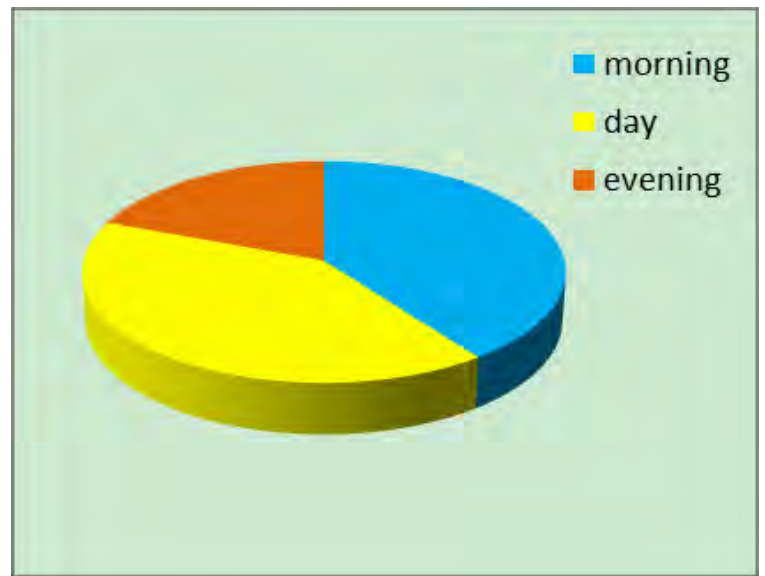

Fig. 3. Image of the road in the view of Chinese students. The time of day.

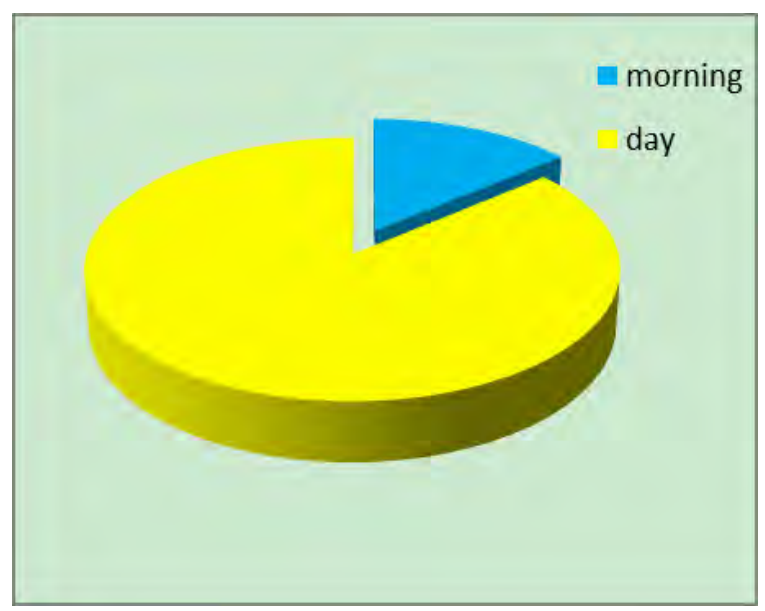

Fig. 4. Image of the road in the view of Russian students. The time of day.

c) Long journey conception: One of the questions in the task was which road can be called long or short. With "length" being a multi-meaningful concept, the length of the road does not only deal with expressing the distance, but also with characterizing the time parameters. The answers of both Russian and Chinese students can be divided into groups with relation to covering a certain distance, duration over a period of time, emotional attitude, and difficulties faced on the way. The listed below are the typical, repeated answers given by the students.

The examples provided by Russian and Chinese respondents defining a long road are:

- Distance: "great mileage"; "more than 400 km"; "from Vladivostok to Moscow"; "from Moscow to Sochi by car" (28\%) (Russian students); "a long road - there is no end to be seen (19\%) (Chinese students).

- Duration: "it takes a lot of time"; "long"; "you have to have a snack on the way" (15\%) (Russian students) "it either takes a lot of time or presents severe difficulties" (18\%) (Chinese students).

- Emotional attitude: "boring"; "eventful"; "tiring but interesting" (14\%) (Russian students); "a long road the one that seems boring" (26\%) (Chinese students). 
- Difficulties faced: "a long road is difficult"; "it is the one that makes you feel exhausted, out of breath"; "the one which is physically and morally challenging" (43\%) (Russian students); "difficult work, challenge" (37\%) (Chinese students).

"Achieving a goal always presupposes the raise of social, mythological or sacred status ... The difficulty of the way is its integral permanent property; going along the way, overcoming problems is already an achievement" (V. N. Toporov) [18]. This idea makes it clear why the large percentage of Russian students (43\%) associates the long road with the difficulties that might take place. Speaking of Chinese students, they share this association to some extent.

"How do I understand a long road? It is such a road that seems boring to me" - says a Chinese student. This is completely in line with the attitude of a Russian person who needs space and finds a long road boring and tiring.

d) The shortness of the way: The following statements were used to define a short road:

- Distance: "short distance"; "in the yard"; "the road to a corner shop"; "near your home" (22\%) (Russian students); "What is "close"? — "at home" (5\%) (Chinese students).

- Duration: "less than two hours driving"; "less in time"; "when time passes quickly"; "at night when you sleep"; "with a book on a train"; "does not matter how long it is - you just do not notice it" (36\%) (Russian students); "it does not take long" (40\%) (Chinese students).

- Emotional attitude: "carelessness"; "for pleasure"; "does not make you feel tense"; "fun and enjoyable, no matter how long it is"; "feel at ease, the way home"; "as a short life - it can be upsetting" (36\%) (Russian students); "a short road - cheerful" (43\%) (Chinese students).

- Difficulties faced: "less tiring" (6\%) (Russian students); "easy business or work" (12\%) (Chinese students).

As we see, for both Russian and Chinese students a long road is the one that is associated with difficulties and overcoming them, it lacks positive emotions, while a short road is short in time and full of emotions that are mostly positive.

Determining the length of the road with time characteristics (long in distance equals long in time) is typical of the archaic and mythopoetic worldview of Russian people. In the answers given by Chinese students, we observe the length of a road being measured by the time spent on the way. Space and time are inseparable from each other here, as they form a single space-time continuum.

e) Road as a life: One of the Chinese students notes that the road theme for a person starts "at the moment of birth", "at the beginning of life". The metaphorical understanding of life as a road/path is inherent in both
Chinese and Russian cultures. The space shapes a person's life directing them on the way, helps to embody and understand their destiny through moving, hence the representatives of Russian culture get such associations: a short road is a short life (one of the answers: "like a short life, thee road can be upsetting"). This may imply the inability to achieve one's life goals, follow one's own path and overcome difficulties.

\section{CONCLUSION}

Conducting the surveys of the kind, aimed to identify matching or controversial components of the images of one's native culture and the culture of the second language is of special interest for teachers of the Russian language as a foreign language. Such association experiments "make it possible to collect the data indicating national and cultural markers of the language and the features of the ethniclinguistic consciousness," notes I. V. Privalova [13].

The described experiment has shown that, despite the contrast of visual images of a road in the worldview of Russian and Chinese students (modern, comfortable, wellorganized roads for Chinese students and the disorder and uncertainty for Russian students, as well as different colors used in descriptions), their emotional and evaluative components related to the space-time attitude on a road/path have a lot in common. Here are, for example, the lines from "The Ancient Song" from the "Han Songs by Yuefu":

"Farther and farther is my home,

My belt is getting loose.

I yearn shedding tears,

My heart is a worn-down road." [3]

These similar perceptions enable teachers to find the common grounds that help to bring Chinese students closer to an adequate perception of Russian images, and the image of a road/path in particular, as it is one of the most significant images of Russian culture.

\section{REFERENCES}

[1] Balkind E.L. Chronotope in fine arts // Scientific notes of Taurida National V.I. Vernadsky University / Series "Philosophy. Culturology. Political science. Sociology". Vol. 26 (65). 2013. № 4. P. 251.

[2] Bakhtin M.M. The forms of time and chronotope in a novel. Essays on historical poetics // Issues of literature and aesthetics. Moscow:KhudozhestvennayaLiteratura. 1975. P. 234.

[3] Braginsky I. (Under general editorship). Literature of Ancient China // Poetry and Prose of the Far East / Library of World Literature. Moscow:KhudozhestvennayaLiteratura. 1973. pp. 301-302, 312.

[4] Gachev G.D. National images of the world. 1988. P. 87.

[5] Gogol N.V. Dead Souls. // Collected. ed. in 7 vols. Moscow: Khudozhestvennaya Literatura. 1985. Vol. I. Ch. 7. P. 12.

[6] Kroll Yu.L. Sima Qian - the historian / Ed.-in-chief L.P. Delyusin. Moscow: Nauka. 1970. - 447 p.

[7] Martynov D. E. Perceptions of historical time in the traditional culture of China in the Han times // Dialogue with Time. 2012. Issue. 41. P. 198 
[8] Mikitchenko E.S. Associative experiment as a way of revealing the national and cultural content of lexical associations // Rusistika '99. International conference on the 2nd anniversary of the Society of Vietnamese Russianists and Teacher's Day in Vietnam. - Moscow. 1999. P. 60.

[9] Mikitchenko E.S. Psychological content and emotional assessment of mental perception of a road/path by Chinese students. Russian language in a multicultural space: monograph. Moscow: RosNOU, 2014. pp. 266-269.

[10] Mikitchenko E.S., Liu B. Expressing the color symbolism of Chinese culture in visualizing the image of a road // At the intersection of languages and cultures. Current issues of humanitarian knowledge. "University-plus". Kirov. 2016. Issue 2-3 (8). pp. 38-43.

[11] Mikitchenko E.S. Measuring length with mood, and width with light: national and cultural features of the image of a road / / Word. Grammar. Speech: Materials of the VI International Scientific and Practical Conference "Text: Problems and Prospects: Aspects of the Study for Teaching the Russian Language as a Foreign Language". Moscow: MAX Press, 2015. - Issue. XVI. pp.387-390.

[12] Plungyan V. A. Time and Times: to the Question of the Number Category // Logical Analysis of the Language: Language and Time. Moscow: Indrik, 1997. pp. 158-169.

[13] Privalova I. V. Language consciousness: ethnocultural markers (Theoretical and experimental research): Thesis abstract. Moscow. 2006. P.5.

[14] Rubtsov N.M. The old road // Russia, Russia! Stay safe. Poems. Comp. by Safronov V.I. Moscow: Voenizdat, 1992. P. 24.

[15] Serikov A.E. Perception of time in Chinese culture // Bulletin of the Samara Humanitarian Academy. Series "Philosophy. Philology". 2016, Issue. 2 (20). P.50.

[16] Stefansky E. E. Concept "Doba" "time, period, era" and binary opposition "Pami" "memory" - "Zapomi $\mathrm{m}$ " 'oblivion' in M. Kundera's novel "The Book of Laughter and Forgetting" // Bulletin of the Samara Humanitarian Academy. Series "Philosophy. Philology". 2015. Issue. 1 (17). P. 110.

[17] Stefansky E. E. The concept of "Kolo" 'circle' in M. Kundera's novel The Book of Laughter and Forgetting // Cultural Codes in Consciousness and Language: an International Collection of Scientific Works on Linguistic Culturology, ed. E. E. Stefansky. Samara. 2015. P. 95.

[18] Toporov V. N. Space and Text // Text: semantics and structure. Moscow: Nauka. 1983. pp. 258-259.

[19] Fedorov M. A. Perception of time in Russian and American cultures (conceptual analysis of Russian and English phraseology). Ulan-Ude: Buryat State University. 2011. pp. 34-42.

[20] Yakimovich A. O. On the construction of space in the modern picture // The Space of the Picture: Collection of articles / Comp. N. O. Tamruchi. Moscow:SovetskyKhudozhnik. 1989. P. 6. 